\title{
Bacteriological profile and antibiotic susceptibility pattern of Neonatal Septicemia in Kanti Children Hospital, Nepal
}

\author{
Deepeshwara Nepal, Sumit Aggrawal, Sushan Shrestha, Ajit Rayamajhi \\ Department of Paediatric Medicine, Kanti Children Hospital, Maharajgunj, Kathmandu, Nepal.
}

\begin{abstract}
Background: Neonatal sepsis is one of the major causes of neonatal morbidity and mortality globally. Current neonatal mortality rate of Nepal is $21 / 1000$ live birth which is higher than that of the global average of 19.2 and slightly lower than the regional (South East Asia). Pathogenic strains of neonatal sepsis varies from place to place and also from time to time, so it is very important to know the common pathogens and its resistant pattern locally. The aim of this study is to find out the hospital based frequency of neonatal sepsis and characterize the bacteriological profile along with their sensitivity and resistance pattern. Materials and Methods: This is a retrospective study done in Kanti Children Hospital, Kathmandu, Nepal over the period of one year starting from July 2018 to June 2019. All culture positive cases were enrolled in the study and their sensitivity pattern were analyzed. Results were expressed as percentage, mean, P-Value and Odds Ratio. Results: A total of 107 cases were culture positive among 1064 probable sepsis accounting 10.05\%. Predominant microorganism isolated in this study were staphylococcus aureus 66(61.7\%), Klebsiella spp. 15(14\%), Esherichia Coli 7(6.5\%) followed by Acinatobacter spp 6(5.6\%). Most of the Gram positive organisms were resistant to Ampicillin, Cetazidime, Cefotaxime and sensitive to Gentamicin, Amikacin, Imipenam, Vancomycin, Ofloxacin, and Tigecyclin. Whereas Gram negative organisms are resistant to Cephalexin, Ampicillin, Piperacillin/Tazobactum, Cefotaxime and sensitive to Tigecyclin), Vancomycin Chloramphenicol and Colistin. Conclusion: There was striking similarity in bacteriological profile in both early onset as well as late onset neonatal sepsis. Most of the pathogens were resistant to WHO first line antibiotics Ampicillin and also the resistance is increasing even in 3rd generation Cephalosporin.
\end{abstract}

Key words: Antibiotics, microorganism, neonatal sepsis, resistant.

\section{Correspondence to:}

Dr. Deepeshwara Nepal

Senior Consultant Pediatrician and Associate

Professor of Pediatrics

Kanti Children Hospital, Maharajgunj, Kathmandu, Nepal.

E-mail: drdeepeshwara@gmail.com

Submitted: June 11, 2020

Accepted: July 18, 2020

To cite: Nepal D, Aggrawal S, Shrestha S, Rayamajhi A. Bacteriological profile and antibiotic susceptibility pattern of Neonatal Septicemia in Kanti Children Hospital, Nepal. JGMC Nepal. 2020;13:2:97-103.

DOI: $10.3126 /$ jgmcn.v13i2.29935

\section{INTRODUCTION}

Neonatal sepsis is diagnosed when generalized systemic feature are associated with pure growth of bacteria from one or more sample sites ${ }^{1}$ One of the major causes of Neonatal mortality in Nepal is neonatal sepsis. ${ }^{2}$ The contribution of neonatal sepsis for such high mortality and morbidity make it quite important study for research as well as action. ${ }^{1}$ The organism causing neonatal sepsis and their antimicrobial susceptibility pattern are highly diverse and vary geographically, temporarily and locally attributed to changing pattern of antibacterial use. ${ }^{3,}$ ${ }^{4}$ In View of growing concern of changing pattern of bacteria and their sensitivity patterns it is essential to do periodic surveillance and to collect local epidemiological data to provide guidance to formulate antibiotic policy in local as well as regional prospective. The aim of this study is to find out the hospital based frequency of neonatal sepsis and characterize the bacteriological profile along with their sensitivity and resistance pattern. 


\section{METERIALS AND METHODS}

This was a hospital based retrospective study conducted in NICU (Neonatal Care Unit) and NIMCU (Neonatal Intermediate Care Unit) at Kanti Children Hospital (KCH) Maharajgunj, Kathmandu, Nepal, over the period of one year from July 2018toJune 2019. KCH is the only one government Pediatric tertiary care center in Nepal. It receives the sick children including neonates from all over the Country. This study was done after the ethical clearance which was obtained from Institutional Review Committee (IRC), of KCH.Ref.No.266. 25 August, 2019. Ethical principles were considered and followed throughout the study. Purposive sampling technique was used in this study. All newborns admitted to the NICU and NIMCU of KCH with positive blood culture during the study period was included in this study. None of the newborns were excluded. A total of 107 cases were included. All necessary information's were collected in predesigned Performa including patient baseline and demographic profiles like age at admission, sex, gestation age, birth weight, parity of mother, mode of delivery, place of delivery, main diagnosis, organism isolated and their sensitivity and resistant patterns. Short term hospital outcome was shown in the form of good out come if the newborn were discharged with complete recovery and poor outcome if the newborn were died. These data were retrieved from medical record section of $\mathrm{KCH}$.

Under all aseptic precautions one to two $\mathrm{ml}$ of venous blood was collected and inoculated in conventional method Brain heart infusion broth (BHIB) containing $9 \mathrm{ml}$ of BHI broth in the final ratio of $1: 10$.The broth is then incubated at 35 to $37^{\circ} \mathrm{C}$ in the incubator aerobically .After overnight incubation one loopful of the broth was sub cultured into blood agar and Mac.Conkey agar respectively and further incubated to look for growth. Repeated subculture was done after 48 hours and 72 hours in Blood agar and MacConkey agar. If no growth was seen after 72 hours of incubation the culture was reported as sterile. If growth was seen, Gram staining was performed to identify the bacteria and, biochemical test was performed for identification and antimicrobial testing was done accordingly. Antibiotic susceptibility was done by using modified Kirby-bauer disc diffusion method according to guidelines of clinical and laboratory standards institute (CLSI).The antibiotics used for sensitivity patterns were ampicillin, amoxicillin, amikacin, cotrimoxazole, chloramphenicol, ciprofloxacin, cefotaxim, ceftazidime ,ceftriaxone, cephalexin, cloxacillin, gentamicin, polymyxinB, ofloxacin, cefixim, cephazolin, piperacillin/tazobactum, imipenam, vancomycin, tobramycin, ampicillin/sulbactum, clindamycin, meropenam, levofloxacin, imipenam, linezolid, teicoplanin, aztreonam, colistin, tigecyclin. Statistical analysis was done by using the statistical package for social science (SPSS) version 20. Data were expressed as percentage, mean, $\mathrm{P}$ value and Odds Ratio with confidence interval of $95 \%$. P-Value was calculated using chi-square test and considered as significant when it is $<0.05$.

\section{RESULTS}

Out of 1064 cases, 107 were found to be culture positive which accounts for $10.05 \%$ incidence of culture positivity. Majority of newborns were delivered at or after 34 weeks of gestation (86\%). Males outnumbered females (71\% vs. $29 \%)$. Almost $90 \%$ of newborns were delivered in health institution. Spontaneous delivery was seen in $64.5 \%$ of cases and majority (64.5\%) of newborns had a birth weight between 2500- 3999 Grams. The average length of stay was $18.82 \pm 13.9$ days (Demographic and clinical parameters are shown in Table 1).

Table 1: Demographic and Clinical parameters

$\begin{array}{ll}\text { Characteristics ( } \mathbf{n}=\mathbf{1 0 7} & \text { Number (\%) } \\ \text { Mother's Age } & 6(5.6) \\ <20 \text { years } & 94(88) \\ 20-35 \text { years } & 7(6.4) \\ >35 \text { Years } & \\ \text { Gestational Age } & 15(14) \\ <34 \text { weeks } & 92(86) \\ \geq 34 \text { weeks } & \\ \text { Parity } & 59(55) \\ \text { Primi } & 48(45) \\ \text { Multi } & \\ \text { Sex } & 76(71) \\ \text { Male } & 31(29) \\ \text { Female } & \\ \text { Place of delivery } & 96(89.7) \\ \text { Institutional } & 11(10.3) \\ \text { Non- institutional } & \\ \text { Mode of delivery } & 69(64.5) \\ \text { SVD } & 36(33.6) \\ \text { LSCS } & 2(1.9) \\ \text { Instrumental } & \\ \text { Birth weight in grams } & 12(11.2) \\ <1500 \text { gms } & 24(22.4) \\ \text { 1500-2499 gms } & 69(64.5) \\ 2500-3999 \text { gms } & 2(1.9) \\ \geq 4000 \text { gms } & \\ \text { Length of Stay } & 52(48.6) \\ <14 \text { days } & 55(51.4) \\ \geq 14 \text { days } & \end{array}$

Among the isolates Staphylococcus aureus (Staph. aureus) was the most frequent isolate accounting for $66(61.7 \%)$ of cases followed by Klebsiella , Escherichia coli (E. Coli), Acinatobacter, Enterobactericiae, Coagulase negative staphylococcus aureus(CONS), Pseudomonas and Enterococcus facium. In case of Early onset neonatal sepsis( EONNS) Staph. aureus was the most common isolate with 
18 cases. This was followed by Klebsiella, Acinatobacter, E. coli, Enterobactericiae, and CONS. Staph. aureus was the most common isolate with 48 cases even in late onset neonatal sepsis (LONNS). This was followed by Klebsiella, E. coli, Enterobactericiae, Pseudomonas, Acinatobacter, CONS and Enterococcus (Table 2).

\section{Table 2: Distribution of isolated organisms}

\begin{tabular}{llll}
\hline Organism & $\begin{array}{c}\text { Frequency of } \\
\text { isolation } \\
\mathbf{n}(\%)\end{array}$ & EONNS & LONNS \\
Staph aureus & $66(61.7)$ & 18 & 48 \\
Klebsiella & $15(14)$ & 8 & 7 \\
E. coli & $7(6.5)$ & 3 & 4 \\
Acinetobacter species & $6(5.6)$ & 4 & 2 \\
Enterobactericiae & $5(4.7)$ & 2 & 3 \\
CONS & $4(3.7)$ & 2 & 2 \\
Pseudomonas & $3(2.8)$ & 0 & 3 \\
Enterococcus faecium & $1(0.9)$ & 0 & 1 \\
Total & $107(100)$ & 37 & 70 \\
\hline
\end{tabular}

Table 3: Antibiotic susceptibility of gram positive organisms

\begin{tabular}{|c|c|c|}
\hline Antibiotics & $\begin{array}{l}\text { Resistant } \\
\text { n (\%) }\end{array}$ & $\begin{array}{l}\text { Sensitive } \\
\text { n (\%) }\end{array}$ \\
\hline Ampicillin & $16(69.6)$ & $7(30.4)$ \\
\hline Ceftazidime & $2(66.7)$ & $1(33.3)$ \\
\hline Cefotaxime & $13(54.2)$ & $11(45.8)$ \\
\hline Meropenem & $2(50)$ & $2(50)$ \\
\hline Clindamycin & $2(50)$ & $2(50)$ \\
\hline Cefepime & $8(47)$ & $9(53)$ \\
\hline Ceftriaxone & $8(44.4)$ & $10(55.6)$ \\
\hline Amoxiclav & $3(42.8)$ & $4(57.2)$ \\
\hline Cephalexin & $8(42.1)$ & 11 (57.9) \\
\hline Ciprofloxacin & 18 (39) & $28(61)$ \\
\hline Flucloxacillin & $7(29.2)$ & $17(70.8)$ \\
\hline $\begin{array}{l}\text { Piperacillin/ TtaactumTazobTazobac- } \\
\text { tum }\end{array}$ & $1(16.7)$ & $5(83.3)$ \\
\hline Chloramphenicol & $2(12.5)$ & $14(87.5)$ \\
\hline Amikacin & $5(8.5)$ & 54 (91.5) \\
\hline Gentamicin & 0 & $5(100)$ \\
\hline Imipenem & 0 & $2(100)$ \\
\hline Vancomycin & 0 & $53(100)$ \\
\hline Ofloxacin & 0 & $8(100)$ \\
\hline Tigecycline & 0 & $3(100)$ \\
\hline
\end{tabular}

Among the various antibiotics which were tested for susceptibility Gram positive organisms were resistant to Ampicillin in $69.6 \%$ of cases followed by Ceftazidime $66.7 \%$. This was followed in descending order of frequency by cefotaxime, Meropenem, Clindamycin, Cefepime, Ceftriaxone, Amoxiclav, Cephalexin, Ciprofloxacin, Flucloxacillin, Piperacillin/tazobactum, Chlorampheniciol and Amikacin accounting for $54.2 \%, 50 \%, 50 \%, 47 \%, 44.4 \%, 42.8 \%, 42.1 \%$, 39\%, 29.2\%, 16.7\%, 12.5\% and 8.5\% respectively. Among the isolates there was no resistance seen for Vancomycin, Ofloxacin, Gentamicin, Imipenem and Tigecycline (Table 3).

Among the various antibiotics which were tested for susceptibility all of Gram negative organisms were predominantly resistant to Cephalexin, followed by Ampicillin, Piperacillin/Tazobactum, Cefotaxim, Ceftriaxone, Ceftazidime, Meropenem, Cefepime, Amikacin, Ciprofloxacin, Ofloxacin, Imipenem, Gentamicin, Polimixin B and Colistin accounting $91.3 \%, 75 \%, 75 \%, 66.7 \%, 62.5 \%, 53.8 \%$, $50 \%, 45.5 \%, 41.7 \%, 40 \%, 33.3 \%, 28.6 \%, 16.7 \%$ and $8.3 \%$ respectively. There was no resistance seen for Vancomycin, Chloramphenicol and Tigecycline(Table 4).

Table 4: Antibiotic susceptibility of Gram negative organisms

\begin{tabular}{lll}
\hline Antibiotics & $\begin{array}{l}\text { Resistant } \\
\mathbf{n}(\%)\end{array}$ & $\begin{array}{l}\text { Sensitive } \\
\mathbf{n}(\%)\end{array}$ \\
\hline Cephalexin & $5(100)$ & 0 \\
Ampicillin & $21(91.3)$ & $2(8.7)$ \\
Piperacillin/ Tazobactum & $12(75)$ & $4(25)$ \\
Cefotaxime & $12(75)$ & $4(25)$ \\
Ceftriaxone & $8(66.7)$ & $4(33.3)$ \\
Ceftazidime & $5(62.5)$ & $3(37.5)$ \\
Meropenem & $7(53.8)$ & $6(46.2)$ \\
Cefepime & $3(50)$ & $3(50)$ \\
Amikacin & $10(45.5)$ & $12(54.5)$ \\
Ciprofloxacin & $10(41.7)$ & $14(58.3)$ \\
Ofloxacin & $2(40)$ & $3(60)$ \\
Imipenem & $2(33.3)$ & $4(66.7)$ \\
Gentamicin & $2(28.6)$ & $5(71.4)$ \\
Polimixin B & $2(16.7)$ & $10(83.3)$ \\
Colistin & $1(8.3)$ & $11(91.7)$ \\
Vancomycin & 0 & $1(100)$ \\
Chloramphenicol & 0 & $4(100)$ \\
Tigecycline & 0 & $11(100)$ \\
\hline
\end{tabular}

There was a significant association between outcome and organism isolated with a p-vale of 0.003 . There were 8 fold odds of having a good outcome whenever an organism was isolated in the admitted cases. Among the Gram positive organisms good outcome was noted in $97 \%$ of cases while poor outcome was noted in 3\% of cases. Among the Gram negative organisms good outcome was noted in $80.5 \%$ of cases while poor outcome was noted in $19.5 \%$ on cases. Looking at the specific organism's good outcome was noted among 64 cases where Staph aureus was isolated. Similarly among isolates of Klebsiella, E. coli, Acinatobacter, Entrobactericiae, CONS, Pesudomonas and Enterococcus good outcome was seen among 9, 6, 6, 5, 4, 3 and 1 case respectively. Similarly poor outcome was noted among most cases isolated for Klebsiella, Staph aureus, and E. Coli accounting for 6, 2 and 1 
cases respectively. Rest of the isolated organisms didn't have poor outcome (Table 5).

Table 5: Comparison of outcome with organism isolated

\begin{tabular}{lllll}
\hline Type of organism isolated & $\begin{array}{c}\text { Good } \\
\text { Outcome } \\
\mathbf{n ( \% )}\end{array}$ & $\begin{array}{c}\text { Poor } \\
\text { Outcome } \\
\mathbf{n}(\%)\end{array}$ & p-value & Odds Ratio \\
Gram Positive & $69(97)$ & $2(3)$ & & 8.32 \\
Gram Negative & $29(80.5)$ & $7(19.5)$ & 0.003 & $(1.63-42.5)$ \\
Total & $98(91.5)$ & $9(8.5)$ & & \\
Specific organisms & & & & \\
Staph aureus & 64 & 2 & & \\
Klebsiella & 9 & 6 & & \\
E. coli & 6 & 1 & N/A & N/A \\
Acinetobacter & 6 & 0 & & \\
Enterobactericiae & 5 & 0 & & \\
CONS & 4 & 0 & & \\
Pseudomonas & 3 & 0 & & \\
Enterococcus faecium & 1 & 0 & & \\
Total & 98 & 9 & & \\
\hline
\end{tabular}

\section{DISCUSSION}

Neonatal septicemia is a life-threatening emergency, and rapid treatment with antibiotics is essential for a favorable outcome. ${ }^{5}$ Neonatal sepsis is a major cause of morbidity and mortality in developing countries like Nepal. The emergence of antibiotic resistant bacteria and its dissemination is exacerbated by inappropriate antimicrobial consumption and precarious living conditions. The most common organisms associated with neonatal sepsis vary with time of infections and geographical location. ${ }^{6}$ Therefore, information on bacteriological profile of neonatal sepsis and effective antimicrobials for its treatment are important to combat neonatal morbidity and mortality issues. Blood culture is still the gold standard for diagnosis of neonatal sepsis, in spite of few drawbacks such as being time consuming, low sensitivity, and possible contamination especially with commensal CONS that could be produced. ${ }^{7}$

Blood culture positivity rate in this study was $10.05 \%$ (107 out of 1064). A wide range of culture positivity rate have been reported in the past (6.1 to $40 \%$ ) in various studies conducted in different place and times. ${ }^{6,8,12}$ Similar findings have also been reported by K.M. Zaidi (1.7-33/1000 live birth with rates in Africa 20 and south Asia around 15/1000 live birth. ${ }^{13}$ Low incidence of culture positivity in this study could have been because of prior use of antibiotics since we receive extramural cases from all over the country. Inadequate blood volume, less blood to BHIB ratio, less and poor Microbiological yields could be additional causes for the fewer yields.

Males outnumbered females, $76(71 \%)$ vs. $31(29 \%)$ in our study is comparable to other studies conducted in the past. 6-12

This study showed commonest organism to be Gram Positive. Similar finding of bacterial yield has also been reported by several other studies in the past. ${ }^{6,8-10}$ Predominant pathogen found in our study was staphylococcus aureus consisting $62 \%$ followed by Klebsiella spp. 14\%.There were striking similarities between early onset and late onset neonatal sepsis .Among Gram positive organism Staphylococcus aureus was the leading causative agent consisting 67(63\%) followed by CONS. High incidence of staph aureus sepsis has also been reported by in various other studies conducted in Nepal at different times. ${ }^{6,12}$ A recent Indian population based study conducted in a large no of neonates $(12,622)$ in Odissa $^{14}$ also have reported Staph. aureus as the most common organism causing LOS. On the contrary CONS was the commonest causative organism in EOS in other studies. ${ }^{15,18}$ One study in Nepal however have reported different bacteriological profile; he has been reported predominance of CONS in EONNS and Gram negative bacteria in LONNS. ${ }^{17}$

The second most common organism isolated in our study was Klebsiella followed by E. coli. This was in consist ant with findings of various studies in our country. ${ }^{9,10,18,19}$ However, it was contrary to various studies from India which reported different bacteria. ${ }^{15,19,20-22}$ Shankar et al $^{23}$ conducted metaanalysis on neonatal sepsis and antibiotics in South Asian countries in India, Pakistan, Bangladesh, Nepal and Srilanka between 2000-2018. They found predominance of Gramnegative bacteria namely Klebsiella spp. and E. Coli followed by methicillin resistant Staph. aureus (MRSA). Incidence of Klebsiella spp was 53.6\% (50.7-56.5\%) in India,33 \% (3.0$63.0 \%$ ) in Nepal and $60 \%$ in Srilanka. Among pathogens in hospital, Gram negative was 63\% (Klebsiella 23\%, E. coli 14\%, and Acinatobacter 8\%). Common Gram-positive pathogens were Staph aureus (20\%) and CONS (9\%). Zaidi et.al. ${ }^{13}$ did the meta-analysis on hospital acquired neonatal infection in developing countries (Africa, South East Asia, South Asia, Latin America, Carabian middle east and central Asia) over 14 years (1990 to 2004) found Gram negative organism to occupy $60.5 \%$ of the total burden (Klebsiella spp. 22.8\%, E. coli 12.2\%, Pseudomonas 7.9\%, Enterobacter spp. 5.5\%, Acinatobacter spp.5.0\%, Citrobacter 1\%, Salmonella $0.9 \%$, Proteus $0.8 \%$, Serrtia $0.1 \%$, N. Meningitis $0.1 \%$, and Haemophilus spp. 0.1\%). All Gram-positive organism occupy $35.5 \%$ (Staph. aureus 16.3\%, CONS $12.1 \%$ and other streptococcus $2.3 \%$, Group D streptococcus $1.7 \%$, S. Pneumonie $0.5 \%$, Group A streptococcus $0.2 \%$, Listeria spp. $0.1 \%$ and others $0.7 \%$.). ${ }^{13}$ The spectrums of pathogens in developing countries including Nepal, in newborn are quite different 
from that of developed countries where GBS, E. coli and CONS were the predominant. Researches from other parts of world also revealed $G B S$ as the predominant organism causing early onset sepsis. ${ }^{24,25}$ Study done in Australia by Gowda H found that vast majority (73\%) of late onset neonatal sepsis were caused by Gram positive bacteria, of which $39.8 \%$ of them were CONS. ${ }^{26}$ Among Gram negative isolate Klebsiella was the most common causative agent followed by E.coli which is was similar to other studies. ${ }^{10,17}$

The high rate of Staph. aureus and Klebsiella and other Gram negative organism found in our study even in EOS in hospital born babies may have been because of hospital acquired rather than maternal acquired infection. In such a situation, the cause of spread of Staph is the poor hand hygiene of health care workers. Similarly, high incidence of Gram negative bacteria including Klebsiella spp. to cause outbreak. Is that they thrive well in multiuse containers of medications, liquid soap, other antiseptic solutions, tap water and inadequately disinfected and sterilized health care equipment's. Hence, in order to control and prevent epidemic outbreaks, we have to consider all these facts and should take appropriate measures.

In this study almost $70 \%$ of Gram positive pathogens were resistant to Ampicillin which is WHO recommended $1^{\text {st }}$ line antibiotic. Alarmingly they were even resistant to $3^{\text {rd }}$ generation cephalosporin i.e. (Ceftazidim 67\%, Cefotaxime $54 \%$, Cefepime $47 \%$ and Ceftriaxone $47 \%$ ). On the other hand they are sensitive to aminoglycosides and quinolone (Gentamicin 100\%, Vancomycin 100\%, Amikacin 92\% and Ofloxacin 100\%). They were also quite sensitive to Piperacillilin/Tazobactum, Imipenam and Tigecycline.

Regarding Gram negative bacteria they were highly resistant to Ampicillin (91.3\%), Cefotaaxim (75\%) Piperacillin/ Tazobactum (75\%) Gentamicin (71\%), Cetazidim (63.\%). However, they were sensitive to Tigecyclin (100\%), Chloroamphenicol (100\%), Colistin (100\%), Polymyxin B (83.\%) .It has been pointed out that antibiotics resistance have reached an alarming level in developing countries in neonatal nurseries. ${ }^{13}$ It has been estimated that almost $70 \%$ of organism in hospital setup are resistant to WHO recommended $1^{\text {st }}$ line antibiotics i.e. ampicillin and gentamicin. Emerging resistant bugs have been reported even in $2^{\text {nd }}$ and $3^{\text {rd }}$ lines antibiotics such as cefotaxim resistant to E. coli (40\%), and Klebsiella in (51\%), likewise $56 \%$ of Staph. aureus has been reported as MRSA. ${ }^{1}$

Several factors like poor infection control practice, use of multidose vials antibiotics, use of stock intravenous fluids, gross overuse of empirical antibiotics, inappropriate and prolong use of antibiotics are some of the reasons for high prevalence of NNS and antibiotics resistance. In short, it can be considered as obvious outcome of the failure of the health care system.

Hence, in resource poor setting like ours, some cost cutting measures to reduce NNS would be national level program in antenatal care to reduce the rate of preterm and LBW delivery by providing good antenatal care, adequate nutrition to the pregnant mothers, preventing maternal anemia and infection. Intrapartum care like reducing number of $\mathrm{p} / \mathrm{v}$ examination, treatment of chorioamnionitis, and various intervention that reduce the rate of perinatal asphyxia would also be important measures to reduce NNS. Postpartum care that would be useful to prevent NNS are early and exclusive breastfeeding, Kangaroo Mother Care, umbilical cord care, creation of "step down" neonatal care unit for LBW and stable babies and cut down of empirical antibiotics to three days if the neonates are healthy looking and septic screen are negative and blood culture are negative. ${ }^{13}$

\section{CONCLUSION}

Bacteriological profiles are similar in both early onset as well as late onset neonatal sepsis. Most of the pathogens were resistant to WHO first line antibiotics and there is increasing trends of drugs resistance even in third generation cephalosporin and beta lactam drugs. Retrospective nature and the incomplete antimicrobial testing are the main drawbacks of this study. Large scale multi-centric study within the country covering all the provinces is needed to formulate the antibiotic policy in our country.

ACKLODGEMENT: The authors would like to express deep thanks and sincere appreciation to all the staff of NICU and NIMCU of Kanti Children Hospital for their supports and medical record section of $\mathrm{KCH}$ for providing record files for data collection.

\section{CONFLICT OF INTEREST:}

None declared

\section{Funding:}

No any funding source.

\section{REFERENCES}

1. Shah GS, Budhathoki S, Das BK, Mandal RN. Risk factors in early neonatal sepsis. Kathmandu University medical journal. 2006;4(2):187-91. PMID: 18603896.

2. Fottrell E, Osrin D, Alcock G, Azad K, Bapat U, Beard J et al. Cause-specific neonatal mortality: analysis of 3772 neonatal deaths in Nepal, Bangladesh, Malawi and India. Arch Dis Child Fetal Neonatal. 2015;100:439-476. 
DOI: 10.1136/archdischild-2014-307636

3. Shehab El-Din E, El-Sokkary M, Bassiouny MR. Epidemiology of neonatal sepsis and implicated pathogens: a study from Egypt. Bio Med Research International. 2015; 11:1-11. DOI:10.1155/2015/509484

4. Sivanandan S, Soraisham A, Swarnam K. Choice and duration of antimicrobial therapy for neonatal sepsis and meningitis. International Journal of Pediatrics. 2011; 20:1-9. DOI:10.1155/2011/712150

5. Kairavi JD, Saklainhaider SM. Neonatal Septicemia: Bacterial Isolates\& Their Antibiotics Susceptibility Patterns. NJIRM. 2010;1(3):12-6.

6. Shrestha RK, Rai SK, Khanal LK, Mandal PK. Bacteriological study of neonatal sepsis and antibiotic susceptibility pattern in Kathmandu. Nepal Med Coll J. 2013;15:71-3.

7. Eman M, Shehab El-Din R, Mohamed M, Adel ElS, Mohamed R B, Ramadan H. Epidemiology of Neonatal Sepsis and Implicated Pathogens. Egypt BioMed Research International. 2015;12:1-11. DOI:10.1155/2015/509484

8. Shrestha NJ, Subedi KU, Rai GK. Bacteriological profile of neonatal sepsis: A hospital based study. J Nep Paedtr Soc. 2010;31(1):1-5. DOI: 10.3126/jnps.v31i1.4158

9. Chapagain RH, Acharya R, Shrestha N, Giri BR, Bagale BB, Kayastha M. Bacteriological Profile of Neonatal Sepsis in Neonatal Intermediate Care Unit of Central Paediatric Referral Hospital in Nepal. J Nepal Health Res Counc. 2015; 13(3):205-8. DOI: 10.33314/jnhrc. v0i0.673

10. Mishra D, Chapagain RH, Bhattarai S, Jha NK, Mishra R. Clinico-pathological profile of late onset neonatal sepsis in a tertiary centre of Nepal. MJSBH. 2019; 18(2):2-6. DOI:S10.3126/mjsbh.v18i2.23517

11. Shrestha S, Lama L, Sharma A, Shrestha GS. Neonatal Sepsis: Bacteriological Profile and Antibiotic Sensitivity Pattern in Nepal Medical College. Nepal Med Coll J. 2015;17:43-6.

12. Adhikari N, Shah PK, Acharya G, Vaidya KM. Bacteriological profile and associated risk factors of neonatal sepsis in Paropakar Maternity and Women's Hospital Thapathali, Kathmandu. Nepal Med Coll J. 2014;16(2-4):161-4.

13. Zaidi AKM, Huskins WC, Thaver D, Bhutta ZA, Abbas Z,
Goldmann DA. Hospital acquired neonatal infection in developing countries. Lancet. 2005;365: 1175-88. DOI: 10.1016/50146-6736(65)71881X

14. Panigrahi P, Chandel DS, Hansen NI, Sharma N, Kandefer S, Parida S. et al. Neonatal sepsis in rural India: timing, microbiology and antibiotic resistance in a population-based prospective study in community setting. J Perinatol. 2017; 37(8):911-21. DOI:10.1038/ jp.2017.67

15. Muthukumaran N. Mortality profile of neonatal deaths and deaths due to neonatal sepsis in a tertiary care center in southern India: a retrospective study. Int J Contemp Pediatr. 2018; 5:1583-87. DOI: 10.18203/2349-3291. ijcp20182569

16. Prasad PS, Nataraj G, Nanavati RN. Changing trends in bacterial spectrum of neonatal sepsis at a tertiary care teaching hospital. J Evolution Med Dent Sci. 2016;5(65):4628-33. DOI: 10.14260/ jemds/2016/1055

17. Gurung B. Shrestha LP. Bacterial profile of Early versus Late Onset Neonatal sepsis and its antimicrobial Susceptibility: A 1-year retrospective study in tertiary level teaching Hospital of Nepal. JIOM. 2017;39(3):406.

18. Gyawali N, Sanjana RK. Bacteriological Profile and Antibiogram of Nepnatal Septicemia. Indian J Pediatr. 2013;80(5):371-4. DOI: 10.1007/S12098-012-0911-9

19. Verma P. Neonatal sepsis: Epidemiology, clinical spectrum, recent antimicrobial agents and their antibiotic susceptibility pattern. Int J Contemp Pediatr. 2015; 2(3):176-80. DOI:10.18203/2349-3291. ijcp20150523

20. Jyothi P, Basavaraj MC, Basavaraj PV. Bacteriological profile of neonatal septicemia and antibiotic susceptibility pattern of the isolates. J Nat Sc Biol Med. 2013;4:306-9. DOI:10.4103/0976-9668.116981

21. Bandyopadhyay T. Distribution, antimicrobial resistance and predictors of mortality in neonatal sepsis. Journal of Neonatal-Perinatal Medicine. 2018;11: 145-53. DOI: 10.3233/NPM-1765

22. Shankar MJ. Neonatal sepsis in South Asia: huge burden and spiraling antimicrobial resistance. BMJ. 2019;364:5314. DOI: 10.3233/NPM-1765

23. Lamba M, Sharma R, Sharma D, Choudhary M, Maheshwari RK. Bacteriological spectrum and 
antimicrobial susceptibility pattern of neonatal septicemia in a tertiary care hospital of North India. The Journal of Maternal-Fetal \&Neonatal Medicine. 2016;29:3993-8. DOI:10.3109/14767058.2016.1152 251

24. Weston EJ, Pondo T, Lewis MM, Cleary PM, Morin C, Jewell B, et al. The Burden of Invasive EarlyOnset Neonatal Sepsis in the United States. Pediatrc Infect Dis J. 2011;30(11):937-41. DOI: 10.1097\%2FINF.0b013e318223bad2
25. Hesam A. Multidrug -resistant organisms in neonatal Sepsis in two tertiary neonatal ICUs, Egypt. J Egypt Public Health Assoc. 2016;91:31-8. DOI: 10.1097/01. EPX.0000482038.76692.3

26. Gowda H, Norton R, White A, Kandasamy Y. Late Onset Neonatal Sepsis - A 10 Year Review from North Queensland, Australia. The Pediatric Infectious Disease Journal. 2017;36(9):883-8. DOI: 10.1097/ INF.0000000000001568 